\title{
Characterizing the Theory of Energy Transition in Luxembourg, Part Two-On Energy Enthusiasts' Viewpoints
}

\author{
Ali Arababadi ${ }^{1} * \mathbb{C}$, Stephan Leyer ${ }^{1}\left(\mathbb{D}\right.$, Joachim Hansen $^{1}$, Reza Arababadi ${ }^{2}$ and Gloria Pignatta ${ }^{3}(\mathbb{D}$ \\ 1 Department of Engineering, University of Luxembourg, L-1359 Luxembourg, Luxembourg; \\ Stephan.Leyer@uni.lu (S.L.); Joachim.Hansen@uni.lu (J.H.) \\ 2 Department of Energy, Institute of Science and High Technology and Environmental Sciences, \\ Graduate University of Advanced Technology, Kerman 7631818356, Iran; rarababa@asu.edu \\ 3 School of Built Environment, Faculty of Arts, Design, and Architecture, University of New South \\ Wales (UNSW) Sydney, Kensington, Sydney 2052, Australia; g.pignatta@unsw.edu.au \\ * Correspondence: arababadi.a@gmail.com
}

Citation: Arababadi, A.; Leyer, S.; Hansen, J.; Arababadi, R.; Pignatta, G. Characterizing the Theory of Energy Transition in Luxembourg, Part Two-On Energy Enthusiasts' Viewpoints. Sustainability 2021, 13, 12069. https://doi.org/10.3390/ su132112069

Academic Editors: Farshid Keynia and Azim Heydari

Received: 17 September 2021

Accepted: 28 October 2021

Published: 1 November 2021

Publisher's Note: MDPI stays neutral with regard to jurisdictional claims in published maps and institutional affiliations.

Copyright: (c) 2021 by the authors. Licensee MDPI, Basel, Switzerland. This article is an open access article distributed under the terms and conditions of the Creative Commons Attribution (CC BY) license (https:// creativecommons.org/licenses/by/ $4.0 /)$.

\begin{abstract}
The energy transition is a certain phenomenon in the future of the world. However, exploring the existing literature suggests that public considerations have not been analyzed in Luxembourg yet. A widespread move from the conventional energy system based on fossil fuels into a new energy system with renewable energy could not occur successfully without the strong support of the public. Characterizing a theory of transition was intended to fill in the gap of knowledge of the field. To ground the built theory, it is necessary to collect as much empirical data as possible. The applied methodology to collect data was to run a survey. Public groups in a variety of job statuses were invited to take part in the survey. The employed method to analyze the data was a combination of qualitative analysis with the pragmatic theory of truth. Overall, the number of collected responses reached 96. Notably, people did not imagine the future differently. They showed a lack of optimism in the future. The findings confirm that the necessity of energy transition is fairly far from people's considerations. It is a big concern that the authors would like to highlight.
\end{abstract}

Keywords: energy transition; theory of transition; public viewpoints; demand-side; future; Luxembourg

\section{Introduction}

Thinking about the future in a scientific manner is often characterized by an illusion of knowledge, which affects the way of planning and acting strategically to shape the future [1]. However, the future is a fundamental but virtual phenomenon of time that can be addressed in hypothetical terms because it simply has no factuality [2].

To think about the future scientifically, we have to accept that we cannot know the future because of its vague aspects. By admitting this trait of the future, the function of anticipation is highlighted [3].

Indeed, the anticipation of the future is based on available knowledge but is not the same as knowing the future, in everyday life as well as in science. There are two common tools to express the anticipations, elaborating an idea in a theory template and generating scenarios [1]. The former method is noted in this study. In fact, the occurrence of the pandemic led us to think about whether the public is ready to enter a new era and live differently.

Creating illusion in the case of future energy issues begins with knowing basic requirements relevant to future needs. Protecting the environment and non-disrupting economic growth have been reported as requirements [4]. However, it is proceeded with knowing that uncertainties exist on the supply and demand side. Improving energy technologies to harness and store renewable energies are examples on the supply side [5]. Challenges in spreading the use of electric vehicles and the electrification of residential buildings have 
caused several uncertainties on the demand side [6]. Above all, a big question mark exists on the role of the political issues [7]. These are indicative factors, which determine the scale of changes in the energy system. Future uncertainties challenge the reliability of the current energy system. To respond to these likely challenges, the global society has proposed a solution called energy transition.

There is no formal or generally accepted hierarchy of meanings but the term energy transition is used most often to clarify the changes in the composition of primary energy supply, the gradual shift from a specific pattern of energy provision to a new state of an energy system [8]. To develop its concept, the issue has been addressed from different viewpoints. These viewpoints include studies focused on socio-technical transitions path dependency from existing systems of environmental reform and governance shifting end-user values and behaviors and political economy constraints of equity and justice. Apart from these academic approaches, various organizations track "energy indicators" to quantitatively monitor the performance of energy systems at global, national, and local levels [9-13]. The work on transition patterns [14,15] seeks to conceptualize the underlying dynamics that cause such non-linear systemic shifts in terms of threshold behavior and non/linear cause-effect mechanisms [16]. The significance of the paper is to highlight some future concerns, which have rarely been noticed, by constructing theories on energy enthusiasts' viewpoint.

Beyond different theoretical definitions of the energy transition, the strong support of the public has been emphasized as necessary to successfully execute the transition $[17,18]$. However, there is a large number of studies conducted to assess the acceptance of different energy technologies from the public's viewpoint. Several researchers have studied and explained the emitted signals by people. The purpose is to clarify to what extent people are open to the new energy debates [19-21]. Two categories are recognized in the existing literature. The first category focused on the acceptability of different technologies to harness energy sources as a whole or individually on the supply side [22,23]. In the second category, acceptance issues of different applications relevant to the demand-side were processed [24,25]. However, the considered theory was suggested regarding two major issues in Luxembourg.

- $\quad$ Luxembourg is a net importer of energy. More than $86 \%$ of needed energy in Luxembourg is imported [26].

- There is a weak signal between the growth of price and reduction of electricity consumption, low energy price elasticity, in Luxembourg [27]. This could be a symptom of high inertia of residents to gradually change their energy habits.

The availability of the mentioned issues in the context of Luxembourg would make Luxembourg vulnerable in the case of emerging from an energy crisis. Moreover, observing awkward living conditions after the pandemic outbreak led us to hypothesize that the necessity of different future lifestyles because of energy concerns has not been understood by the public.

The built theory was constructed with a pessimistic viewpoint and to ground the theory, a survey methodology was applied.

For this purpose, people with various backgrounds were invited to participate in the survey to reach different viewpoints as much as possible. Future images depict citizens' preferences and perceptions, which in turn may be converted into individual or political actions that will become part of the transition and change the future [28]. However, inviting people solely to increase the number of participants or spreading a blind survey was avoided.

It is believed that people have a better understanding of what they could feel directly impact, such as daily life issues, rather than some non-identical concepts such as new energy carriers with indefinite applications [29]. Therefore, the questions in the survey were limited to the demand side issues. It was asked to what extent participants are worried about the present energy issues and why and where the changes need to happen; 
put simply, whether energy transition is something that people think about at all, and if so, what their considerations about energy transition are.

The paper aimed to characterize the theory of transition in Luxembourg from the participants' viewpoint. Indeed, building the theory has vital implications for political research. The first one is related to the contribution of theoretical ideas to shape the considered questions. The second performance of constructing the theory is to anticipate answers [30].

Energy transition is a phenomenon with an abstract concept but with plentiful unsorted information. By applying processes to sort the available data, clarity and the applicability of results will be increased [31]. The considered procedure to develop the theory of transition in the study was extracted from pragmatic constructivists' consideration. The reason for the method was the assumption of how the perspective of transition is constructed. It is believed that the transition is a shared vision of society members. Pragmatic constructivists use the same concept to generate knowledge to describe the world. Pragmatists emphasize creating knowledge through shared meaning or the kinds of "joint actions" or "projects" that need different people to be involved [32].

This study is an effort to generate knowledge to manage the transition in the macro and micro scale. Managing the transition is composed of problem structuring, visioning, pathway development, agenda-building, and concrete experimentation [33-35]. This study was aimed at structuring the problem. It explored the participants' viewpoints about the limited aspects of the future on the demand side. To the best of the authors' knowledge, there is no published literature in the scope of the study in the context of Luxembourg.

The remainder of this paper is organized into six sections. First, an overview of the energy system in Luxembourg is presented. Second, we describe the theorizing process and the data collection and methods used in our analyses. In the third section, we present the results. Then, the interpretations of the results are explained. Finally, the readers are provided with a discussion of the results.

\section{Overview of the Energy System in Luxembourg}

Luxembourg's total final energy consumption (TFEC) amounted to 3.65 Mega tons oil equivalent (Mtoe) in 2017 (the latest year of available data) [26]. TFEC peaked at 4.09 Mtoe in 2005 and declined by $10.67 \%$ in the 12 years to 2017. Figure 1 shows the changes after 1990. As shown in Figure 1, oil is the biggest portion of energy sources in Luxembourg, which is used mostly in the transportation sector [26].

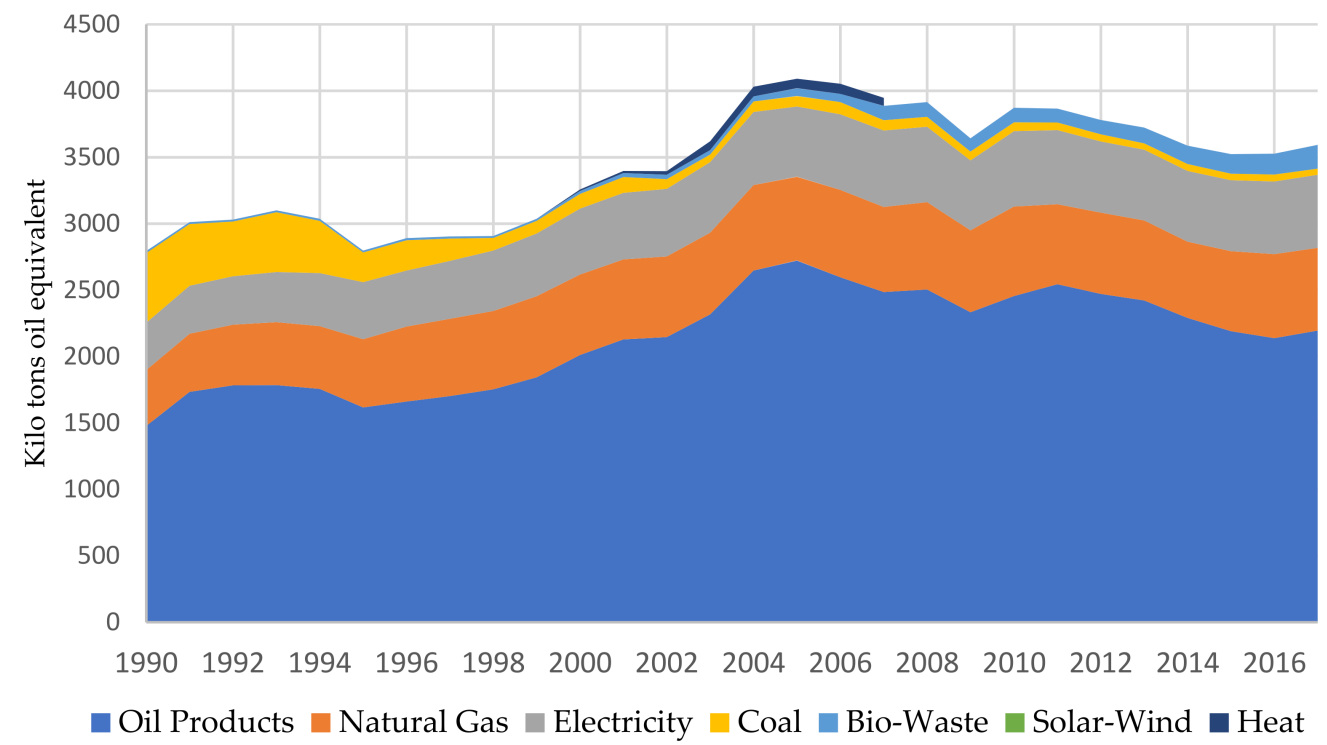

Figure 1. Total final energy consumption by sources in Luxembourg (1990-2017) [36]. 
The considerable share of oil consumption in the energy system is alarming for greenhouse gas (GHG) emissions. The historical record of the emission of the gases is shown in Figure 2.

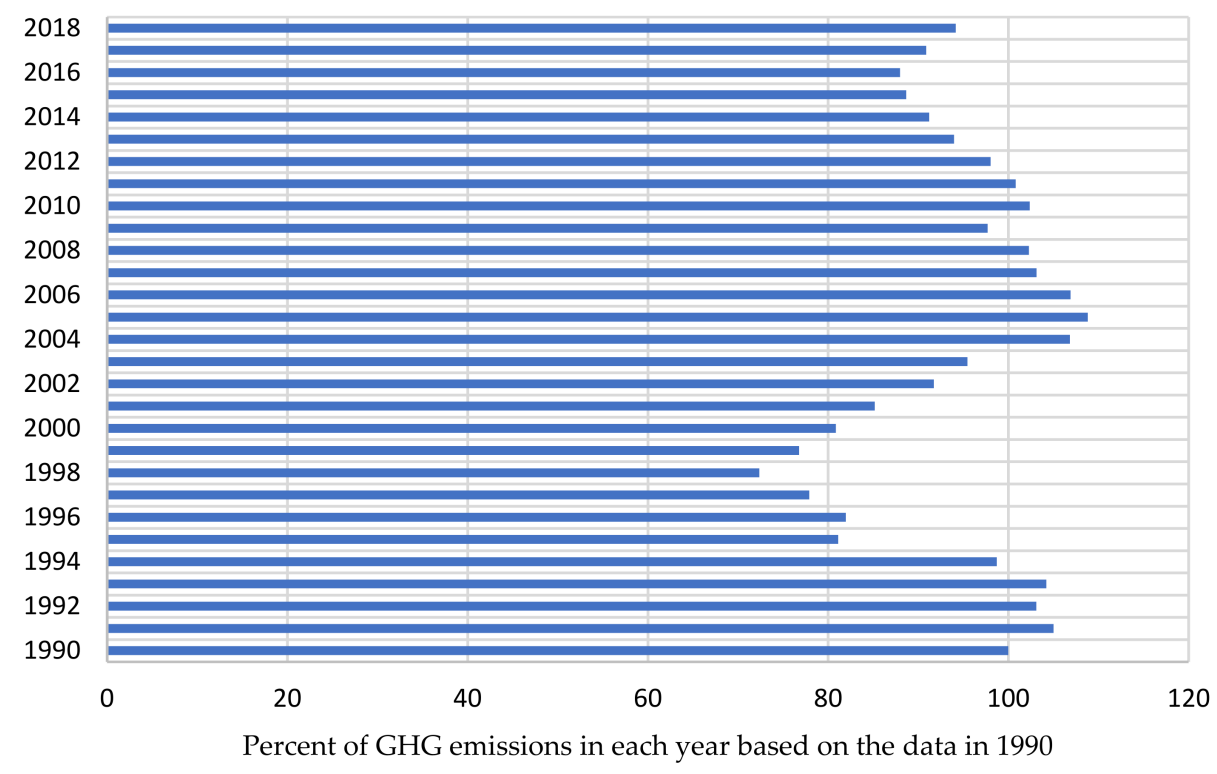

Figure 2. GHG emissions in the Luxembourg database year 1990 [36].

As seen, the emissions of GHGs in Luxembourg in recent years is a few percentages lower than the level of recorded data in 1990. However, effort is needed to continue, because the EU has set a binding climate target for 2030: reducing GHG emissions by at least $40 \%$ compared to 2005 [37]. More than half of the emissions in Luxembourg come from the transport sector. Low fuel tax in Luxembourg has caused a fuel tourism phenomenon. In this case, many commuters from neighboring countries cross the borders just to refuel. It is considered the main reason for the growth of GHG emissions in the transport sector in Luxembourg [38].

\section{Method}

\subsection{Theorizing Process}

The theorizing process was composed of two main steps. In the first step, the hypothesis was formed and the second step was about justifying it using empirical data [39].

The general goal of theorizing is to elaborate an idea or what is called in literature 'abduction' [40]. This means observing a fact and then professing what the idea is about and highlighting the fact. The purpose of theorizing is to guess right or as mentioned in the literature, to express a kind of scientific intuition [41].

At first, a theory regarding the contextual factors in Luxembourg was built. Later, to ground the built theory the viewpoints of a group of the public were explored. For this purpose, the survey methodology was used and detailed in Sections 3.2-3.4.

\subsection{Survey Design}

The survey methodology was applied in the study to collect data with the possibility of receiving people's considerations in their own words. The survey was conducted by asking people's viewpoints about some aspects of the energy transition while expressing some likely consequences of its occurrence as the possible answers. Moreover, an option was embedded in the answering part for getting any other opinions to support the idea of thinking unlimitedly.

Based on the literature, surveys were used for three purposes: exploratory, descriptive, and explanatory [42]. The considered goal in the first type is to investigate a particular issue or topic area without predetermined notions of the expected responses. The goal of 
the second type is to describe the perception of respondents and the association of their characteristics with a system. The purpose of the last type is to explain or to predict one or more hypothesized relationships between some characteristics of respondents and the whole system.

The conducted survey in this study aimed to investigate the future energy perspective without any preferences in responses. It is categorized as an exploratory survey template, where the design is mostly qualitative. The survey aimed to seek inputs from respondents with fixed-end questions. The open-end questions were used to improve the clarity of the selected responses. It focused on how participants understand certain aspects of the energy system.

According to existing literature, there are several methods for running similar studies, by telephone interviews, or written questionnaires, personally named or unnamed interviews, and so forth $[43,44]$. In this study, an online survey and written questionnaires were applied to collect data.

The participants were selected based on the research purposes and the main measure was what they could add to develop the topic. As such, individuals with specific characteristics were requested to take part. It is considered a purposeful sampling. It is a technique widely used in qualitative research for the identification and selection of information-rich cases for the most effective use of limited resources [45]. This involves identifying and selecting individuals or groups of individuals that are especially knowledgeable about or experienced with a phenomenon of interest [46]. In addition to knowledge and experience, the importance of availability and willingness to participate, and the ability to communicate experiences and opinions in an articulate, expressive, and reflective manner were emphasized in the literature $[47,48]$. For example, to study the effects of music on the performance of professional athletics, one can employ purposeful sampling where only individuals known to be professional athletics and who listen to the music are selected for inclusion [49].

For participating in the survey, two properties for participants were determined. The first one was to have relevant knowledge of the field and the second was to be highly educated and interested. Ignoring these properties to choose participants may cause useless expansion of the population of participants with unconscious responses. All invited participants in the survey had a job in Luxembourg and are classified as follows.

In the first group, people were engaged in energy issues in Luxembourg. It was assumed that they have the same concern about recognizing the properties of future energy issues with enough knowledge to participate.

The second group included just highly educated people or researchers in different domains interested in future energy topics. In this group, different backgrounds were included, such as investment, financial, banking, steel consultant, computer science, data science, bioengineering, waste management, transportation, and law.

The population of participants was affected by the considered conditions for participating in the survey. The number of participants in the survey reached 96. Conditional participation considerably decreased the sample size, but the maximum number of nonanswered questions was no more than one in any of the received responses. The intention was to find a variety of insights for the issues in question. The variety of considerations are effective for constructing a comprehensive platform to develop the theory of the transition in Luxembourg. It was a practical application of the pluralistic approach to derive the knowledge in the case.

It should be noted that there is always a risk of reporting opinions about climate change and some other fundamental issues that would not emerge outside the survey setting [48]. Regarding the challenge of external validity, we planned to ask indirectly about issues that would be more favorable for participants on paper. 


\subsection{Survey Structure}

Going through the literature reveals that there are three key characteristics of the past energy transitions [50]:

- Change in primary energy sources is happening.

- There is a need for new technologies or fuels.

- $\quad$ The driving force for the transition is internal.

Indeed, the research questions were designed based on these key properties of historical transition and the built theory. The questions were presented in the survey to address research questions in an understandable format for participants. The following research questions were addressed with six questions in the survey, presented in Table 1.

Table 1. Overview of survey questions and response options.

Questions

1. How will Luxembourg be different after the energy transition?
Response options

(a) Higher rate of employment; (b) Less pollution; (c) Generation of non-hydroelectricity locally; (d) Reduced energy cost; (e) Higher penetration of intelligent systems into life; (f) Change in composition of industries in Luxembourg; ( $\mathrm{g}$ ) Other-describe please

(a) Very important; (b) Somewhat important; (c) Not important. Why?
2. How would you describe the energy transition as an issue for the residents of Luxembourg?

3. Which features of future society do you like most?

4. In which sectors do you feel there is an urgent need to change?

5. What do you think about the main barriers to energy transition in Luxembourg in relation to your work or the work of your organization?

6. Where do you expect that the conventional cycle of energy consumption will change significantly? (a) Mobility-introduction of smart vehicles;

(b) Mobility-introduction of new fuels; (c) Heating-introduction of new fuels; (d) Heating-introduction of intelligent systems for improving controllability; (e) Heating-introduction of energy efficient electric appliances; (f) Electricity-development of solar PV;

(g) Other-describe please

(a) Lack of social awareness; (b) High cost of efficient options; (c) Lack of policy clarity from the government; (d) Lack of consistent support from the government; (e) Other-describe please

(a) Residential—introduction of smart electric appliances;

(b) Residential-introduction of batteries; (c) Transportation-change in purpose of movement; (d) Industry-coupling of cooling needs in industrial site with heating needs of residential;

(e) Other-describe please

\section{Do you have any further suggestions}

for consideration?

To keep the consistency in responses, some choices for each question were given. However, for further comments, an option with "other-please describe" was offered. The survey results contributed to responding to the following questions.

RQ1: What are the characteristics of the future in Luxembourg? The key properties with which people will characterize the future energy system.

RQ2: To what extent are people ready for the big changes? A sensible change, which happens for example by emerging an idea such as the Internet or smartphone.

RQ3: What are the preferences of people concerning future energy in Luxembourg? What are those popular features of the future?

RQ4: Which changes are vital? What are those required changes in the energy field that need to be done in the future?

RQ5: To what extent are people aware of different difficulties in implementing the energy transition in Luxembourg?

RQ6: How much do people think about fuel switch as occurred in the previous transitions?

RQ7: Why does energy transition need to happen in Luxembourg (According to participants' viewpoints)? 
The questions and response options are shown in Table 1.

Participants were invited to respond to six questions and share their general comments about the issue in the seventh question. The last part provided the participants an opportunity to formulate their answers freely in their own words, and not just follow the given responses.

Nonetheless, as reported in the literature, running the survey in an open-end type certainly requires more effort to complete but the received data are richer and more nuanced [51]. Moreover, in the free template response, participants can express what is important to them and provide us with their priority list of concerns based on their pure thoughts.

\subsection{Analyzing Data}

The selected research method to process the data can be best explained as a multiapproach in analyzing people's viewpoints. The qualitative analysis was based on pragmatic methodology, which used evidence from the literature to support the deductions.

The pragmatic constructivism as the employed approach in this study has an inherent assumption. Based on its notion, it is believed that reality has an intersubjective concept through different meanings and understanding of society [52]. Therefore, it is a need to hear many considerations to make some predictions about the dominant thinking in society.

To characterize the theory of transition, the basis for recognizing a truth needs to be explored.

In any complicated puzzle, it is up to the knowledge developers to argue if and when they can also agree that they accept a given solution to be 'true' [53], even if the agreement is temporary and for a restricted purpose.

It is also discussed that the means for ascertaining such a 'truth' is to sustain the dialogue among theorists and practitioners. The considered method is to make a connection between the concept of truth and acceptance [54].

The pragmatic constructivist believes that cognitively organized concepts are required to know how different actors in a system may interact [32,53]. Therefore, they keep their focus on the reasons to support the theory. In abstract, according to pragmatic constructivists, the notion of the energy transition is considered a non-discoverable issue. It consists of general principles that require modifications according to the existing potentials and limitations.

In this research, qualitative analysis was employed to generate inductive reasoning to ground the hypothesis. The study was conducted with a qualitative method to focus on the variation in prevailing thoughts about the future.

Applying statistical methods allows us to make a comparison through the results and to show how the results are related or different [55]. However, the main purpose of this study was to represent various opinions about the future and then to interpret the possible meaning of each viewpoint and discuss the impact of dominant opinions on the future. Comparison of attitudes is not meaningful for the considered purpose. Therefore, the study shows dominant thoughts about the issue and none of the common quantitative approaches was used to interpret the data. Moreover, interpreting the considerations and how they affect the decision-making in different scales was pursued. The research was planned to show how people think about the changes in the energy system. The conducted research is consistent with previous studies of this purpose, as a practice of pluralistic strategy to generate knowledge about the area of inquiry [56].

Consistent with the pragmatism notion, the study was an effort to explore people's considerations about the acceptance issue of different aspects of the future energy system in Luxembourg. It was devised to represent how people imagine the future, more precisely, to find out how the participants characterize energy transition. 


\section{Results Presentation}

\subsection{Imagining the Future in Luxembourg after Energy Transition}

In the first question, people were asked to conceive how Luxembourg might be different after the energy transition. Climate change attracted attention, significantly. More than $25 \%$ of the participants believed that the future will not face a challenge such as greenhouse gas emissions anymore. Assuming a highlighted role of intelligent systems in everyday life was conceived of by one-quarter of participants. One out of five voters believes that green electricity generation will be developed. Imagining the future with a different composition of industries or with lower energy costs or a higher rate of employment had less priority for voters. An overview of the results is shown in Figure 3.

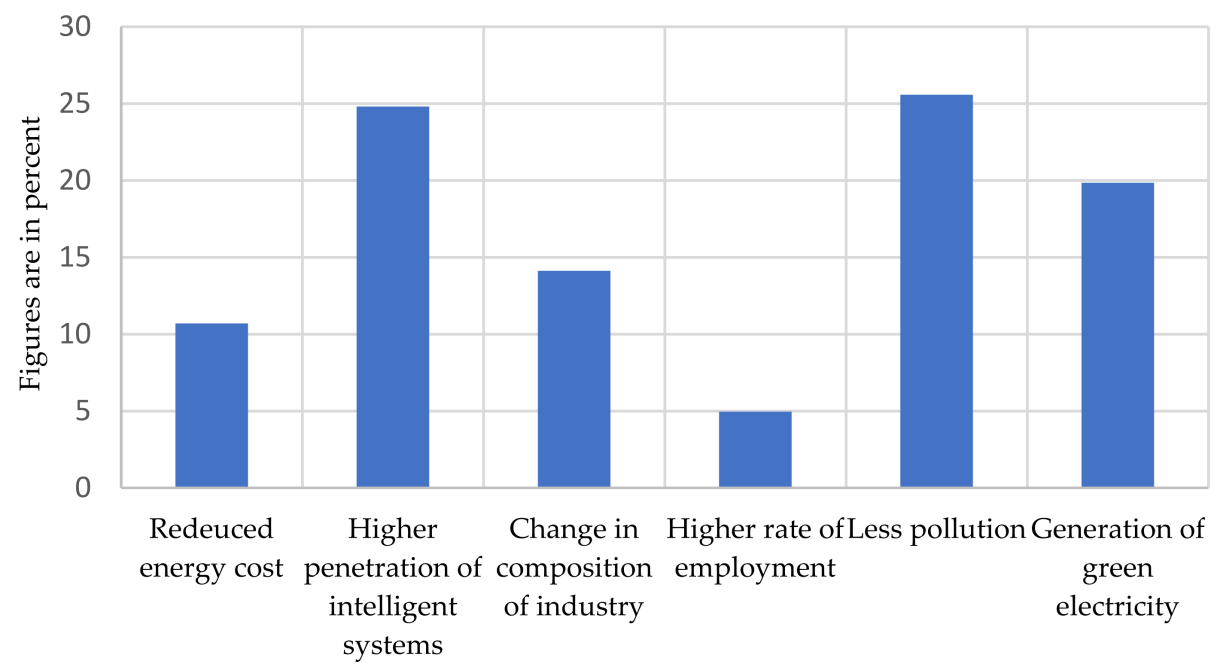

Figure 3. Future Luxembourg at a glance-responses to question 1.

\subsection{To What Extent Is It Important for the Transition to Happen in Luxembourg?}

In the second question, people were asked to make comments about the importance of the energy transition happening.

Just $42 \%$ of participants viewed the occurrence of transition as a very important issue. Based on the received responses, the majority of people believed that transition is a moderately important issue in Luxembourg but is not a priority. According to the provided description by the participants, the climate change issue is the main reason behind this selection. A numerical comparison is shown in Figure 4.

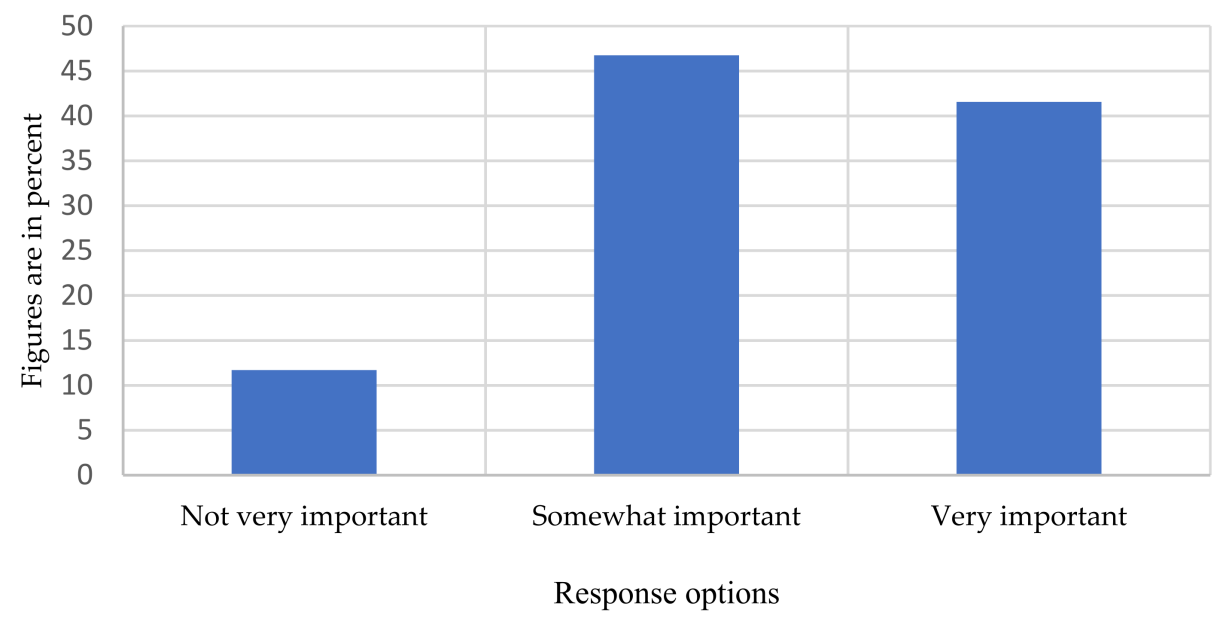

Figure 4. How important is the energy transition in Luxembourg? Answers to question 2. 


\subsection{Popular Features of the Future in Luxembourg}

In this question, people were asked to explain the favorable properties of the future. In other words, how do people tend to describe the future? As found in the results of Section 4.2, participants had a higher interest in a clean environment. A meaningful difference in choosing the second and third options exists against the first option. The justifying reason for the difference is to show an extreme opinion just on paper [48]. Changing lifestyle and experiencing the growth of the penetration of smart systems into life were the second and the third preferences. Low-cost energy was the fourth preference of participants. At the bottom of the priority list, higher individual income and a higher rate of employment were observed with the least responses, in that order. The results are shown in Figure 5.

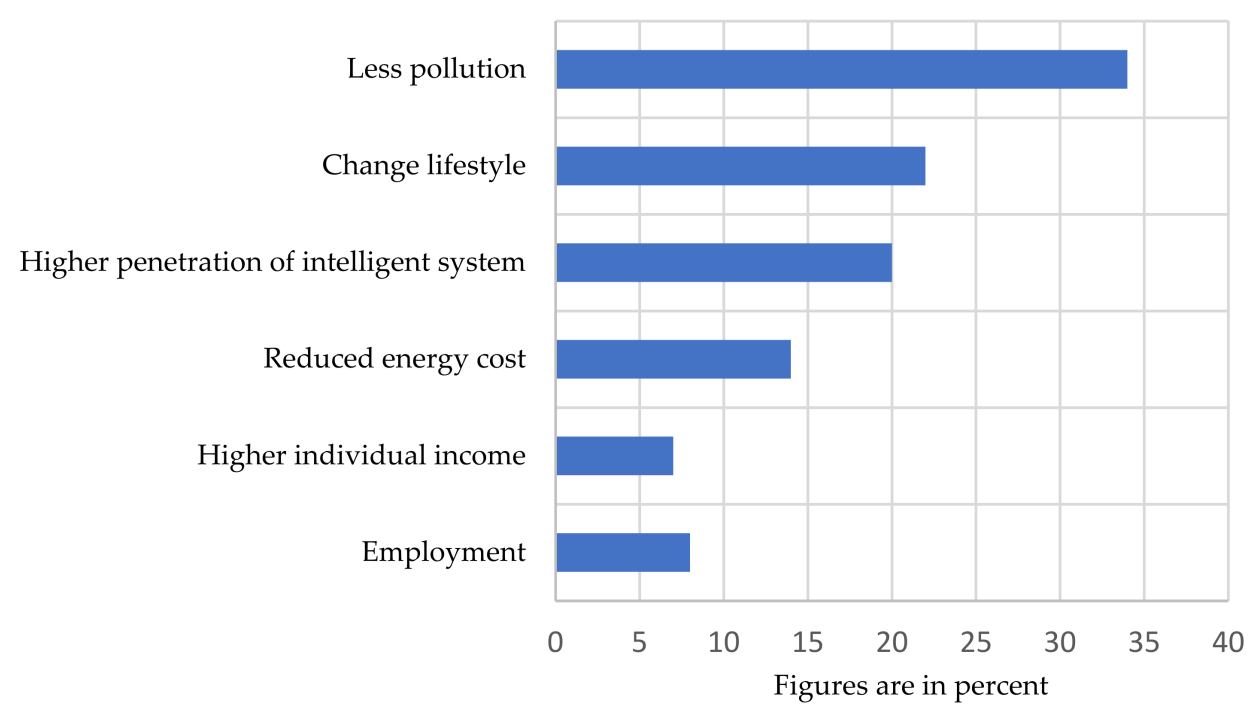

Figure 5. Popular features of the future-answers to question 3.

\subsection{Where Urgent Changes Need to Happen}

In this query, the participants were asked to choose from the provided list of potential changes in everyday life. Based on the results, it was believed that the biggest problem in Luxembourg exists in the transportation sector. The fuel switch strategy was introduced as the favorite option to solve the problem. The next choice with a high number of responses was to generate electricity by solar PV. The low share of smart vehicles in Luxembourg was in the third position for responses. Switching fuel in the residential section was the next choice for changing. An overview of the results is depicted in Figure 6.

\subsection{Main Barriers to Change in Energy Domains}

In this part, the participants were asked about the preventive parameters to engage in the required changes in the energy field. People had the opportunity to select one or more options. Based on responses, the high cost of efficient options was introduced as the main parameter that prevents people from involvement. Lack of awareness was in second position in the number of participants who cared about it. Insufficient support from the government was positioned in the third rank. Finally, a group of people considered that Luxembourg's government does not have a clear policy about future changes. A numerical comparison of the options is presented in Figure 7. 


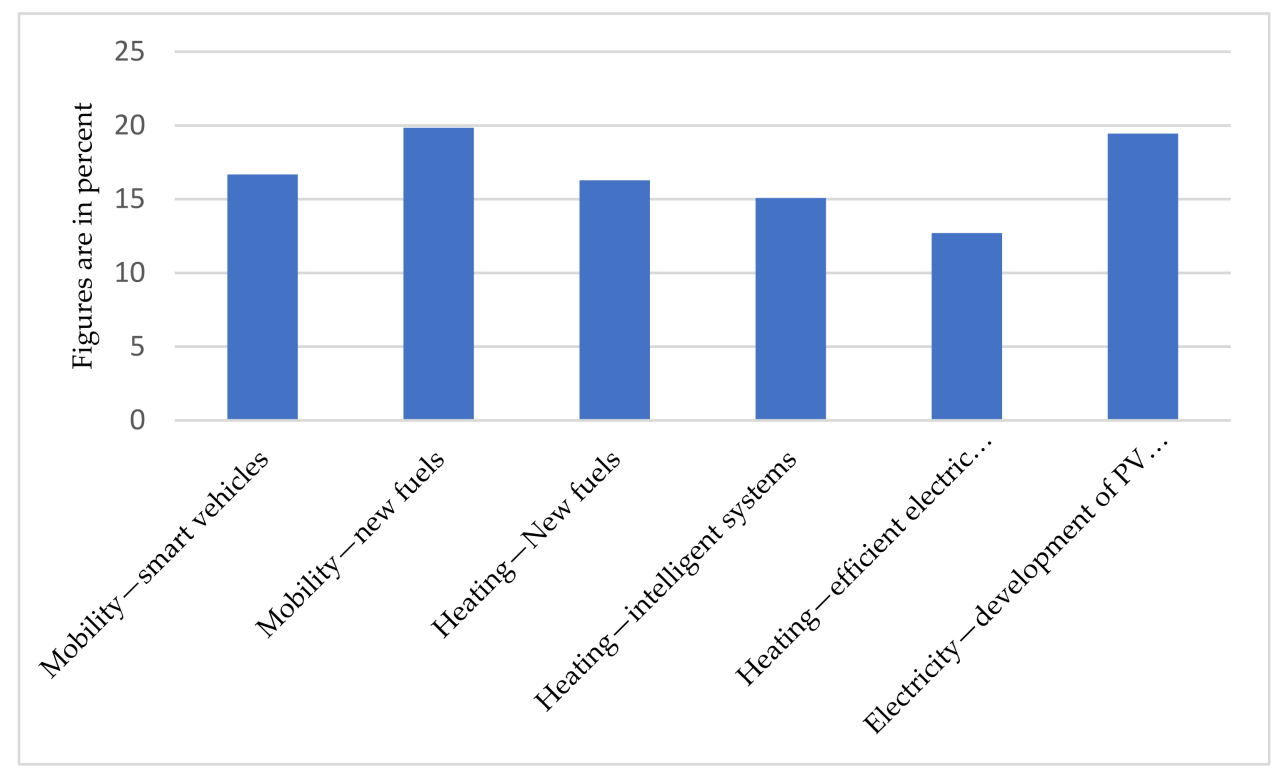

Figure 6. Where urgent changes need to happen-answers to question 4.

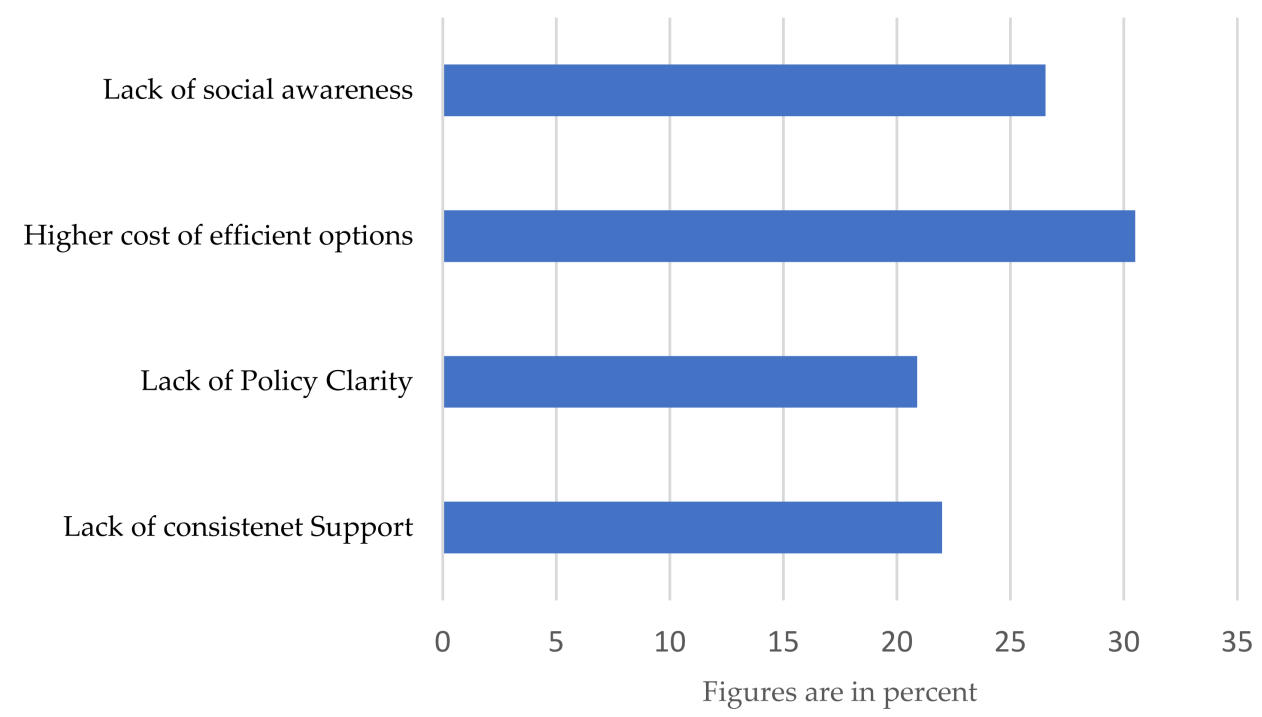

Figure 7. Main barriers to energy transition-answers to question 5.

\subsection{How People Think about Changes That They Could Contribute}

The last question was planned to explore the tendency of people to be involved in energy change debates. The feedback of the survey shows that ca. 35\% expect changes in purposes of movement, $25 \%$ in the residential smart-grid domain, $22 \%$ industry-coupling heating with cooling, and finally $19 \%$ in the introduction of batteries in the residential sector. Perhaps the position of the last choice is a bit strange because it is already an accessible option compared to other choices but why it has the least acceptability rate among others is discussed in Section 5.6. The results are demonstrated in Figure 8. 


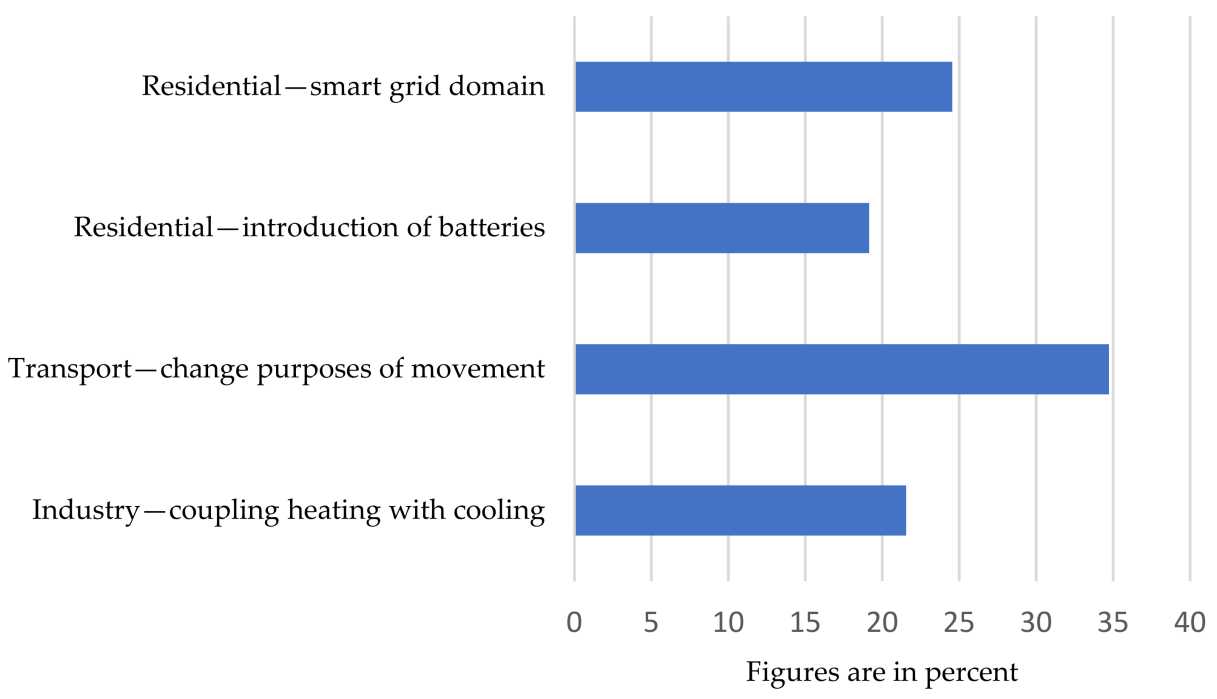

Figure 8. Expected changes in normal cycle of energy consumption-answers to question 6.

\section{Interpretation of the Results}

\subsection{How People Imagine Luxembourg after Energy Transition}

Knowing how people conceive of their socio-technological future can have a strong impact on enabling or constraining new ways of thinking, performing, and living in the world. The importance of how the future is imagined has been emphasized across different domains. As reported, it affects what normally happens and what could happen [57]. To understand the existing challenges and bottlenecks to a transition, people's imagination, expectations, understandings, and ideas about future technologies are highly significant. This theme played a role in the discussion of our participants' ways of characterizing future systems and future change. Notably, the question also assessed the impacts of these participants' considerations on the main aspects of energy system transitions.

In the study, participants drew upon their own experiences to think about the future. Moreover, they generated a sense of how they might feel about different aspects of change, consistent with previous studies [58,59].

Going through the results, it was confirmed that people did not have a feeling of a different future compared to the present. The justifying reason was found by considering the number of participants who did not choose the option. Simply, more than $75 \%$ of participants did not imagine a future with clean air. This analysis of looking in the reverse direction could be generalized to all options to see how people are disappointed with the future. It should be noted that the participants could choose more than one response for any question. The reason might be referred to as the notion of technological pessimism or technological realism [60].

The other reason to express a negative idea is linked to the extent of trust in the involved institutions and organizations that account for control, policymaking, and so forth $[61,62]$. Wynne reported that any reaction to socio-technical issues is often rooted in the recognition of experts with honesty in such institutions that are responsible for controlling the risk processes [61]. Therefore, the results of this part reflect how the negative ideas about socio-technical and governance failure run through the public discourse. It could be recognized as a concern in a likely transition.

\subsection{How Important Is Transition in Luxembourg?}

Usually, energy policies or any other structured recommendations are faced with sensible inertia to be implemented when public support is not strong. Thus, it is important to explore to which extent participants consider transition as a priority. However, the changes are considered acceptable when they do not seriously threaten people's free- 
dom $[63,64]$. On the other hand, people consider changes in the energy system acceptable when consequences are evaluated positively in individual and collective modes $[65,66]$.

The data in Figure 4 show a weak symptom of readiness to changes. It should be noted that the data might be colored by people's value-based judgment and not reflect the real concern of people. Therefore, it is a matter of knowing the judgments. In the case of targeting environmental consequences, the rating will be the same for the people. However, a study reported that changes in concerns might be underpinned by the costs and benefits that people expect from such technologies [67]. Therefore, a deep understanding of recognizing values underlies people's evaluation and acceptability rating. Consequently, increasing awareness among society members about the issue is a need to develop effective interventions.

Furthermore, a lack of trust in involved parties would affect the assessments of people when they have little knowledge [68]. A trustworthy person or group does not mean just having sufficient knowledge and expertise. People assume them to be open and honest when the party endorses values similar to people's values [69]. Therefore, it is expected that the public trusts universities and NGOs more than commercial companies, because the driver of the companies for following an issue is profit-making and could be recognized as a conflict with public interests.

\subsection{Popular Features of Future}

This question was designed to depict the favorable perspective of the transition. Alternatively, this part addresses participants' acceptability concerning the whole energy system change. In general, acceptance can be assumed as an active or passive approval of a definite technology or product [70].

Choosing less pollution or climate change options induced a range of descriptive responses from different forms of doubt to a high level of concern.

A significant number of participants expressed enthusiasm for addressing contemporary problems by doing things differently. It could be supported by considering the number of received hints to changes in lifestyle, and penetration of intelligent systems selected by one-third of participants.

Another interesting point is related to the post-transition condition of the job market. Results show clearly that people do not like to describe the future with an improved job market as a measure.

Reduced energy cost was the fourth most popular option. Showing this low level of interest in the cost problem is a clear signal to the growth of other aspects of transition. People expressed their readiness to accept paying bills more than usual if there is a reason.

Beyond this, the participants made comments freely on the question to link the transition in energy with other possible advancements in the whole aspect. This includes advancement in healthcare, the food industry and crops, establishing energy communities and regenerative medicines, and an increased level of free time due to choosing a different lifestyle.

\subsection{Where Urgent Changes Happen}

Households are consuming 26\% of direct energy in Europe and 19\% in Luxembourg [36]. However, consumption in the transportation sector is higher than in the residential sector. It is $32 \%$ of total consumed energy in the transportation sector in Europe and more than $50 \%$ in Luxembourg. Hence, drawing more attention to the transport sector is normal. In both sectors, the majority of people expect a shift to a new kind of cleaner fuel. Investing in energy efficiencies, such as refurbishments of houses and the adoption of energy-efficient appliances, was mentioned by less than $5 \%$ of participants. This could be interpreted as people being in a waiting mode toward ongoing changes. They expect something new, a fundamental change. 
Nevertheless, just $20 \%$ of people believed that the generation of electricity with the aid of solar PV needs to be developed. Different reasons for being pessimistic were discussed in Section 5.1. The preventive barriers are discussed in the next section.

\subsection{Main Barriers for Energy Transition}

Three factors are reported that prevent people from engaging in energy issues [64].

First, people need to be aware of the requirements and possible ways to contribute to the issue. For instance, in a prevalent topic such as climate change, people have a limited understanding of how they could contribute to being less harmful [71]. In the other cases, people assume that the cause of global warming is more relevant to activities such as industry than to their shares [72]. Similarly, in the curtailment topic, people think that turning off the light instead of efficiency improvement will lead to higher energy saving, while the latter idea is true according to the experts [17]. Therefore, knowledge is highly effective for the evaluation of the pros and cons of energy alternatives.

Secondly, people should be motivated to engage. Indeed, they assess the impact of such behaviors more favorably when the result has more benefit and less cost. People may also take a role in a sustainable energy plan when they feel doing a particular activity will increase their status, no matter how costly it is [73]. Similarly, adopting electric cars with higher cost has the same logic. When the car owner's evaluation of the symbolic aspect is positive, it is done [74]. It is a matter of considering the value of prestige. However, consequences are not limited to the individual but also to collective impacts. People are motivated by being seen as being right in a moral aspect [67]. However, the most important point is the weight of individual and collective consideration of sustainable energy behavior. The existing value in each consequence, and the weight of impact, push people toward different activities. Life goals or ideals are reflected in the context of values [75,76].

Thirdly, people need to be able to do so. Engaging in energy transition issues may be inhibited by various contextual factors. These factors define the cost and benefits of different energy behaviors. Therefore, the factors affect individual motivations [77,78]. For example, the provision of recycling facilities promotes reusing industries [79]. The contextual factors even have deep impacts. In some cases, they make some behaviors simply impossible [80].

In the question, lack of clarity and inconsistency in the policy is relevant to the motivation factor, high cost of an efficient option is summarized in the contextual factor, and lack of social awareness is clearly related to the deficiency of knowledge.

\subsection{Where Are Big Changes Expected to Happen?}

Generally, it is supposed that people do not have the initiative to act or think about energy issues unless some personal benefits are included [81]. Therefore, the question was posed to explore the level of interest of local people in the proposed changes regarding personal benefit concepts. It is a matter of external incentives to encourage people to think about it or even a step further to be involved in it. The incentives are designed to change contextual factors. It is not a matter of just cost issues but the provision of choices with higher pleasure or more benefits [64,82]. As a result, people will get involved in energy issues when such behavior is uniquely rewarding [83]. It suggests that many different encouragements need to be offered to boost wide-scale behavior change. In this question, the generated signals by the introduction of batteries and coupling of heating and cooling capacities are relatively low for individuals. Maybe less personal benefit in the latest options is sensible.

\subsection{Insights in a Free Template from Unlimited Thinking Part}

In the last part of the survey, the governing role of energy in the ongoing transition was commented on. Some people believed that water scarcity and soil degradation are at the same level of concern in Luxembourg. In other words, it was asked to what extent energy manages the changes in Luxembourg. 
The other comment addresses the changes in energy habits in Luxembourgish people. Luxembourg is considered in the top five countries with a high level of income [84]. Therefore, it could be concluded that residents might not be sensitive to marginal changes in energy prices. Therefore, a new pattern for changing habits is needed in rich countries like Luxembourg. It is a matter of finding how to redefine the comfort zone in wealthy countries like Luxembourg.

Another common concern was related to the generation of solar electricity by rooftop solar panels. While Luxembourg is a small country in size, rooftop panels play an important role in the generation of green electricity. However, the sloping roof of buildings with different angles is a limiting factor for reaching the highest efficiency to harness solar energy. Consequently, passing laws to consider energy issues in the future to construct new buildings or renovating old ones becomes necessary.

Finally, redesigning the city with long-term considerations and adapting streets with emerging needs were asserted as comments in this part. Participants mentioned that changing the face of cities with short-term goals is a waste of the public budget.

The last two comments reflected the impact of the energy transition on the appearance of the city, which shows a wide domain of stakeholders of the transition.

\section{Discussion}

Based on collected data, it was found that a remarkable level of negative participants' attitude toward future transition exists. Another interpretation of the participant responses represents that the current world is still good enough. Do not take a risk to change for an unknown future. These interpretations support the built theory in Section 1.

To consciously decide, policymakers need to take care of scientific uncertainties, which are colored by participants' values and specialist knowledge, which in turn are shaped by arguments and debates with colleagues and, more generally, by debates within society [85]. Accepting the theory will lead us to expect conservative reactions toward new features in various domains in society. In a pessimistic case, if the behavior becomes part of the culture in the society, high inertia of the public side to realize the changes would be observed. Alternatively, a lack of public support in society may increase the risk of creating a 'dealbreaker' phenomenon. Analyzing the case might be very context-specific. Nevertheless, increasing awareness about the issue could shed light on the importance of the role and support of the public for future changes. The reasons for negative attitudes to participate in the ongoing energy transition were discussed in Section 5.

The next point is referred to the need for localizing future energy issues based on the real conditions of Luxembourg. Mass media has been working hard to internalize external problems and their efforts more or less have been successful. For instance, pollution and climate change are at the top of the priority concern list of participants about the future, while based on Section 2, the public is less responsible for the greenhouse gas emissions in Luxembourg. This reflection of attention to an exaggerated issue is the art of media.

The third point is to highlight the high level of context dependency of the energy transition that leads us to expect different pathways of transformation in various contexts $[86,87]$. The constructed theory in this study was based on contextual factors, which are apparently different from region to a region. Therefore, the context dependency of the pathways necessitates supporting local studies in each region about the issue.

\section{Conclusions}

The study was carried out in two phases; in the first phase, we formed a theory to address the energy concerns, and in the second phase, we justified the built theory by exploring public viewpoints. For this purpose, a survey methodology was applied to collect the participants' consideration about different aspects of the future energy system in Luxembourg on the demand side. The results and the interpretations were argued in detail with a conservative viewpoint of the authors. It was deduced that conceiving the 
transition causing a better future is not possible for the participants. Therefore, it could be regarded as a warning about public acceptance of a new transition in society.

The other achievement of building a theory is to reflect the range of various responses and meanings. Revealing the public understanding of the concept will affect the flexibility of policymakers to respond to the emerging problems properly, as argued in Section 5.

Author Contributions: Conceptualization, A.A., S.L. and J.H.; methodology, A.A.; validation, A.A., S.L., J.H. and R.A.; writing-original draft preparation, A.A., S.L. and J.H.; writing-review and editing, J.H., R.A. and G.P.; supervision, S.L. All authors have read and agreed to the published version of the manuscript.

Funding: This research received no external funding.

Institutional Review Board Statement: Not applicable.

Informed Consent Statement: Not applicable.

Data Availability Statement: Not applicable.

Conflicts of Interest: The authors declare no conflict of interest.

\section{References}

1. Gabriel, J. A scientific enquiry into the future. Eur. J. Futur. Res. 2014, 2, 31. [CrossRef]

2. Neuhaus, C. Zukunft im Management: Orientierungen für das Management von Ungewissheit in strategischen Prozessen; Carl-AuerVerlag: Heidelberg, Germany, 2006.

3. Habegger, B. Strategic foresight in public policy: Reviewing the experiences of the UK, Singapore, and the Netherlands. Futures 2010, 42, 49-58. [CrossRef]

4. Lahidji, R.; Michalski, W.; Stevens, B. The Long-Term Future for Energy: An Assessment of Key Trends and Challenges. Energy: The Next Fifty Years; Organisation for Economic Cooperation and Development (OECD): Paris, France, 1999.

5. Whittingham, M.S. History, Evolution, and Future Status of Energy Storage. Proc. IEEE 2012, 100, 1518-1534. [CrossRef]

6. Held, A.; Boßmann, T.; Ragwitz, M.; Del Río, P.; Janeiro, L.; Förster, S. Challenges and appropriate policy portfolios for (almost) mature renewable electricity technologies. Energy Environ. 2017, 28, 34-53. [CrossRef]

7. Burke, M.J.; Stephens, J.C. Political power and renewable energy futures: A critical review. Energy Res. Soc. Sci. 2018, 35, 78-93. [CrossRef]

8. Smil, V. Energy Transitions: History, Requirements, Prospects; ABC-CLIO: Santa Barbara, CA, USA, 2010.

9. Geels, F.W. Technological transitions as evolutionary reconfiguration processes: A multi-level perspective and a case-study. Res. Policy 2002, 31, 1257-1274. [CrossRef]

10. Unruh, G.C. Understanding carbon lock-in. Energy Policy 2000, 28, 817-830. [CrossRef]

11. Loorbach, D. Transition Management for Sustainable Development: A Prescriptive, Complexity-Based Governance Framework. Governance 2010, 23, 161-183. [CrossRef]

12. Arababadi, R.; Moslehi, S.; El Asmar, M.; Haavaldsen, T.; Parrish, K. Energy policy assessment at strategic, tactical, and operational levels: Case studies of EU 20-20-20 and U.S. Executive Order 13514. Energy Policy 2017, 109, 530-538. [CrossRef]

13. Arababadi, A.; Leyer, S.; Hansen, J.; Arababadi, R. Characterizing the Theory of Spreading Electric Vehicles in Luxembourg. Sustainability 2021, 13, 9068. [CrossRef]

14. van der Brugge, R. Transition Dynamics in Social-Ecological Systems: The Case of Dutch Water Management; Erasmus MC: Rotterdam, The Netherlands, 2009.

15. Schot, J.; Geels, F.W. Strategic niche management and sustainable innovation journeys: Theory, findings, research agenda, and policy. Technol. Anal. Strat. Manag. 2008, 20, 537-554. [CrossRef]

16. Grin, J.; Rotmans, J.; Schot, J. Transitions to Sustainable Development: New Directions in the Study of Long TermTransformative Change; Taylor \& Francis Ltd.: Abingdon, UK, 2010.

17. Attari, S.Z.; DeKay, M.L.; Davidson, C.I.; DE Bruin, W.B. Public perceptions of energy consumption and savings. Proc. Natl. Acad. Sci. USA 2010, 107, 16054-16059. [CrossRef]

18. Bernauer, T.; Gampfer, R. How robust is public support for unilateral climate policy? Environ. Sci. Policy 2015, 54, 316-330. [CrossRef]

19. Schweizer-Ries, P. Energy sustainable communities: Environmental psychological investigations. Energy Policy 2008, 36, $4126-4135$. [CrossRef]

20. Raven, R.; Mourik, R.; Feenstra, C.; Heiskanen, E. Modulating societal acceptance in new energy projects: Towards a toolkit methodology for project managers. Energy 2009, 34, 564-574. [CrossRef]

21. Wüstenhagen, R.; Wolsink, M.; Bürer, M.J. Social acceptance of renewable energy innovation: An introduction to the concept. Energy Policy 2007, 35, 2683-2691. [CrossRef] 
22. Zoellner, J.; Schweizer-Ries, P.; Wemheuer, C. Public acceptance of renewable energies: Results from case studies in Germany. Energy Policy 2008, 36, 4136-4141. [CrossRef]

23. van der Horst, D. NIMBY or not? Exploring the relevance of location and the politics of voiced opinions in renewable energy siting controversies. Energy Policy 2007, 35, 2705-2714. [CrossRef]

24. Cotton, M.; Devine-Wright, P. NIMBYism and community consultation in electricity transmission network planning. In Renewable Energy and the Public: From NIMBY to Participation; Earthscan: London, UK, 2010; Volume 115.

25. Creutzig, F.; Fernandez, B.; Haberl, H.; Khosla, R.; Mulugetta, Y.; Seto, K.C. Beyond Technology: Demand-Side Solutions for Climate Change Mitigation. Annu. Rev. Environ. Resour. 2016, 41, 173-198. [CrossRef]

26. Statec. Statistics-Grand Duchy of Luxembourg. 2018. Available online: https://statistiques.public.lu/stat/ReportFolders/ ReportFolder.aspx?IF_Language=eng\&MainTheme $=1 \&$ FldrName=4\&RFPath=54 (accessed on 20 January 2021).

27. Arababadi, A.; Leyer, S.; Hansen, J.; Arababadi, R. Characterizing the Theory of Energy Transition in Luxembourg-Part Three. In Residential Buildings. Energy Sci. Eng. 2021. submitted.

28. Vainio, A.; Varho, V.; Tapio, P.; Pulkka, A.; Paloniemi, R. Citizens' images of a sustainable energy transition. Energy 2019, 183, 606-616. [CrossRef]

29. Abrahamse, W.; Steg, L.; Vlek, C.; Rothengatter, T. The effect of tailored information, goal setting, and tailored feedback on household energy use, energy-related behaviors, and behavioral antecedents. J. Environ. Psychol. 2007, 27, 265-276. [CrossRef]

30. Arnold, R. Book Review: Usable Theory: Analytical Tools for Social and Political Research. Teach. Sociol. 2010, 38, 395-396. [CrossRef]

31. Yin, R.K. Case Study Research: Design and Methods, 5th ed.; Applied Social Research Methods Series; Sage Publications, Inc.: Thousand Oaks, CA, USA, 1994.

32. Morgan, D.L. Paradigms lost and pragmatism regained: Methodological implications of combining qualitative and quantitative methods. J. Mix. Methods Res. 2007, 1, 48-76. [CrossRef]

33. Wittmayer, J.M.; Van Steenbergen, F.; Rok, A.; Roorda, C. Governing sustainability: A dialogue between Local Agenda 21 and transition management. Local Environ. 2015, 21, 939-955. [CrossRef]

34. Nevens, F.; Frantzeskaki, N.; Gorissen, L.; Loorbach, D. Urban Transition Labs: Co-creating transformative action for sustainable cities. J. Clean. Prod. 2013, 50, 111-122. [CrossRef]

35. Nevens, F.; Roorda, C. A climate of change: A transition approach for climate neutrality in the city of Ghent (Belgium). Sustain. Cities Soc. 2014, 10, 112-121. [CrossRef]

36. Eurostat. European Statistics. Available online: https:/ /ec.europa.eu/eurostat/web/energy/data/database (accessed on 2 February 2021).

37. European Commission. Climate Action; European Commission: Brussels, Belgium, 2021.

38. Donat, E.Z.; Ayres, A. Assessment of Climate Change Policies in the Context of the European Semester. Country Report: Luxembourg (Covering the Period between February 2013 and November 2013); Publications Office of the European Union: Luxembourg, 2013.

39. Weber, M. Essays in the Methodology of the Social Sciences; Shils, E.A., Finch, H.A., Eds.; and Translators; Free Press: New York, NY, USA, 1949.

40. Wiener, P.P. Essays in the Philosophy of Science; The University of Chicago Press, Philosophy of Science Association: Chicago, IL, USA, 1960.

41. Swedberg, R. Theorizing in sociology and social science: Turning to the context of discovery. Theory Soc. 2012, 41, 1-40. [CrossRef]

42. Kuziemsky, C.; Lau, F. Engaging in eHealth evaluation studies. In Handbook of eHealth Evaluation: An Evidence-Based Approach; University of Victoria: Victoria, BC, Canada, 2017. Available online: https:/ / pubmed.ncbi.nlm.nih.gov/29431951/ (accessed on 20 October 2011).

43. Simon, C.A. Alternative Energy: Political, Economic, and Social Feasibility; Rowman \& Littlefield Publishers: Lanham, MD, USA, 2020.

44. Krohn, S.; Damborg, S. On public attitudes towards wind power. Renew. Energy 1999, 16, 954-960. [CrossRef]

45. Patton, M.Q. Qualitative Research E Evaluation Methods: Integrating Theory and Practice; Sage Publications: Thousand Oaks, CA, USA, 2014.

46. Creswell, J.W.; Clark, V.L.P. Designing and Conducting Mixed Methods Research; Sage Publications: Thousand Oaks, CA, USA, 2017.

47. Bernard, H.R. Research Methods in Anthropology: Qualitative and Quantitative Approaches; Rowman \& Littlefield: Lanham, MD, USA, 2017.

48. Podsakoff, P.M.; MacKenzie, S.B.; Lee, J.-Y.; Podsakoff, N.P. Common method biases in behavioral research: A critical review of the literature and recommended remedies. J. Appl. Psychol. 2003, 88, 879. [CrossRef]

49. Karageorghis, C.I.; Terry, P.C. The psychophysical effects of music in sport and exercise: A review. J. Sport Behav. 1997, $20,54$.

50. Elias, R.J.; Victor, D.G. Energy Transitions in Developing Countries: A Review of Concepts and Literature; Stanford University: Stanford, CA, USA, 2005.

51. Galesic, M.; Bosnjak, M. Effects of Questionnaire Length on Participation and Indicators of Response Quality in a Web Survey. Public Opin. Q. 2009, 73, 349-360. [CrossRef]

52. Merriam, S.B. Qualitative Research and Case Study Applications in Education. Revised and Expanded from "Case Study Research in Education"; ERIC: San Francisco, CA, USA, 1998.

53. Haas, P.M.; Haas, E.B. Pragmatic Constructivism and the Study of International Institutions. Millenn. J. Int. Stud. 2002, 31, 573-601. [CrossRef] 
54. Capps, J. A Common-Sense Pragmatic Theory of Truth. Philosophia 2020, 48, 463-481. [CrossRef]

55. Niroumand, H.; Zain, M.; Jamil, M. Statistical Methods for Comparison of Data Sets of Construction Methods and Building Evaluation. Procedia Soc. Behav. Sci. 2013, 89, 218-221. [CrossRef]

56. Merriam, S.B.; Tisdell, E.J. Qualitative Research: A Guide to Design and Implementation; John Wiley \& Sons: Hoboken, NJ, USA, 2015.

57. McDowall, W.; Eames, M. Forecasts, scenarios, visions, backcasts and roadmaps to the hydrogen economy: A review of the hydrogen futures literature. Energy Policy 2006, 34, 1236-1250. [CrossRef]

58. Brown, N.; Michael, M. A Sociology of Expectations:Retrospecting Prospects and Prospecting Retrospects. Technol. Anal. Strat. Manag. 2003, 15, 3-18. [CrossRef]

59. Macnaghten, P. Researching Technoscientific Concerns in the Making: Narrative Structures, Public Responses, and Emerging Nanotechnologies. Environ. Plan. A Econ. Space 2010, 42, 23-37. [CrossRef]

60. Vydra, S.; Klievink, B. Techno-optimism and policy-pessimism in the public sector big data debate. Gov. Inf. Q. 2019, 36, 101383. [CrossRef]

61. Shackley, S.; Wynne, B. Representing Uncertainty in Global Climate Change Science and Policy: Boundary-Ordering Devices and Authority. Sci. Technol. Hum. Values 1996, 21, 275-302. [CrossRef]

62. Liu, L.; Bouman, T.; Perlaviciute, G.; Steg, L. Effects of trust and public participation on acceptability of renewable energy projects in the Netherlands and China. Energy Res. Soc. Sci. 2019, 53, 137-144. [CrossRef]

63. Leijten, F.R.M.; Bolderdijk, J.W.; Keizer, K.; Gorsira, M.; van der Werff, E.; Steg, L. Factors that influence consumers' acceptance of future energy systems: The effects of adjustment type, production level, and price. Energy Effic. 2014, 7, 973-985. [CrossRef]

64. Steg, L.; Vlek, C. Encouraging pro-environmental behaviour: An integrative review and research agenda. J. Environ. Psychol. 2009, 29, 309-317. [CrossRef]

65. Dietz, T.; Dan, A.; Shwom, R. Support for Climate Change Policy: Social Psychological and Social Structural Influences. Rural. Sociol. 2007, 72, 185-214. [CrossRef]

66. Shwom, R.L. A middle range theorization of energy politics: The struggle for energy efficient appliances. Environ. Politics 2011, 20, 705-726. [CrossRef]

67. Bolderdijk, J.W.; Gorsira, M.; Keizer, K.; Steg, L. Values Determine the (In)Effectiveness of Informational Interventions in Promoting Pro-Environmental Behavior. PLoS ONE 2013, 8, e83911. [CrossRef]

68. Steg, L.; Perlaviciute, G.; Van Der Werff, E. Understanding the human dimensions of a sustainable energy transition. Front. Psychol. 2015, 6, 805. [CrossRef]

69. Earle, T.C.; Siegrist, M. Morality Information, Performance Information, and the Distinction Between Trust and Confidence1. J. Appl. Soc. Psychol. 2006, 36, 383-416. [CrossRef]

70. Bertsch, V.; Hall, M.; Weinhardt, C.; Fichtner, W. Public acceptance and preferences related to renewable energy and grid expansion policy: Empirical insights for Germany. Energy 2016, 114, 465-477. [CrossRef]

71. Bord, R.J.; O'Connor, R.E.; Fisher, A. In what sense does the public need to understand global climate change? Public Underst. Sci. 2000, 9, 205-218. [CrossRef]

72. Whitmarsh, L. Scepticism and uncertainty about climate change: Dimensions, determinants and change over time. Glob. Environ. Chang. 2011, 21, 690-700. [CrossRef]

73. Griskevicius, V.; Tybur, J.M.; Bergh, B.V.D. Going green to be seen: Status, reputation, and conspicuous conservation. J. Pers. Soc. Psychol. 2010, 98, 392-404. [CrossRef]

74. Noppers, E.H.; Keizer, K.; Bolderdijk, J.W.; Steg, L. The adoption of sustainable innovations: Driven by symbolic and environmental motives. Glob. Environ. Chang. 2014, 25, 52-62. [CrossRef]

75. Rokeach, M. The Nature of Human Values; Free Press: New York, NY, USA, 1973.

76. Schwartz, S.H. Universals in the Content and Structure of Values: Theoretical Advances and Empirical Tests in 20 Countries. Adv. Exp. Soc. Psychol. 1992, 25, 1-65.

77. Stern, D.I.; The Role of Energy in Economic Growth. The Oil Drum. 19 October 2011. Available online: http://theoildrum.com/ node/8476 (accessed on 20 October 2011).

78. Lindenberg, S.; Steg, L. Normative, Gain and Hedonic Goal Frames Guiding Environmental Behavior. J. Soc. Issues 2007, 63, 117-137. [CrossRef]

79. Guagnano, G.A.; Stern, P.C.; Dietz, T. Influences on Attitude-Behavior Relationships: A natural experiment with curbside recycling. Environ. Behav. 1995, 27, 699-718. [CrossRef]

80. Corraliza, J.A.; Berenguer, J. Environmental Values, Beliefs, and Actions: A situational approach. Environ. Behav. 2000, 32, 832-848. [CrossRef]

81. Ahuja, D.; Tatsutani, M.; Sustainable Energy for Developing Countries. SAPI EN. S. Surveys and Perspectives Integrating Environment and Society. 2009, Volume 2. Available online: http://journals.openedition.org/sapiens/823 (accessed on 20 October 2011).

82. Geller, E.S. The Challenge of Social Change: A Behavioral Scientist's Perspective. Soc. Mark. Q. 2002, 8, 15-24. [CrossRef]

83. De Groot, J.I.M.; Steg, L. Morality and Prosocial Behavior: The Role of Awareness, Responsibility, and Norms in the Norm Activation Model. J. Soc. Psychol. 2009, 149, 425-449. [CrossRef]

84. World Bank. World Bank Open Data. 2021. Available online: https://data.worldbank.org/country/luxembourg?view=chart (accessed on 5 February 2021). 
85. Scrase, I.; MacKerron, G. Energy for the Future: A New Agenda; Palgrave Macmillan: New York, NY, USA, 2009.

86. Bergek, A.; Hekkert, M.; Jacobsson, S.; Markard, J.; Sandén, B.; Truffer, B. Technological innovation systems in contexts: Conceptualizing contextual structures and interaction dynamics. Environ. Innov. Soc. Transitions 2015, 16, 51-64. [CrossRef]

87. Bridge, G.; Bouzarovski, S.; Bradshaw, M.; Eyre, N. Geographies of energy transition: Space, place and the low-carbon economy. Energy Policy 2013, 53, 331-340. [CrossRef] 